\title{
Study of thrombocytopenia in pregnancy: clinical presentation and outcome at tertiary care rural institute
}

\author{
Jigyasa Singh*, Kalpana Kumari, Vandana Verma
}

Department of Obstetrics and Gynecology, UPUMS, Saifai, Etawah, Uttar Pradesh, India

Received: 28 January 2020

Accepted: 28 February 2020

\author{
*Correspondence: \\ Dr. Jigyasa Singh, \\ E-mail: drjigyasasingh06@gmail.com
}

Copyright: (C) the author(s), publisher and licensee Medip Academy. This is an open-access article distributed under the terms of the Creative Commons Attribution Non-Commercial License, which permits unrestricted non-commercial use, distribution, and reproduction in any medium, provided the original work is properly cited.

\begin{abstract}
Background: Platelet count below 1.5 lakh/cumm is called as thrombocytopenia. After anaemia it is the second most common haematological disorder in pregnancy. It affects nearly 6 to $15 \%$; on an average $10 \%$ of all pregnancies. Gestational thrombocytopenia is a clinically benign thrombocytopenic disorder usually occurring in late pregnancy. It resolves spontaneously after delivery.

Methods: It is a hospital based prospective observational study over a period of 1 year. All pregnant women who attended OPD at the department of obstetrics and gynecology, UPUMS, Saifai for antenatal checkup were included for the study and blood sample was withdrawn.

Results: Out of 263 cases enrolled for study, 90 women were found to have thrombocytopenia, and 173 had normal platelet count. Thus, incidence of thrombocytopenia was 34\%. Gestational thrombocytopenia accounted for majority of cases of thrombocytopenia in pregnancy (50\%) followed by hypertensive disorders $(22.4 \%)$. It was further followed by ITP $(11.11 \%)$ and dengue $(5.5 \%)$.

Conclusions: Gestational thrombocytopenia is the most common cause of thrombocytopenia during pregnancy $(50 \%)$, but other underlying causes must be considered as well. A thorough history and physical examination will rule out most causes.
\end{abstract}

Keywords: Gestational thrombocytopenia, Hemolysis elevated liver enzymes and low platelets, Massive hemorrhage, Puerperal sepsis, Renal failure, Thrombocytopenia in pregnancy

\section{INTRODUCTION}

Platelet count below $1.5 \mathrm{lakh} / \mathrm{cumm}$ is called as thrombocytopenia. ${ }^{1,2}$ After anaemia it is the second most common haematological disorder in pregnancy. ${ }^{3}$ It affects nearly 6 to $15 \%$; on an average $10 \%$ of all pregnancies. ${ }^{1,2,4-6}$ Thrombocytopenia is categorised into mild (platelet count between 1 lakh/cumm to 1.49 lakh/cumm), moderate (50000/cumm-1 lakh/cumm) and severe $(<50000 /$ cumm $){ }^{7}$ In normal pregnancies $7.6 \%$ of women present with mild thrombocytopenia and $65 \%$ of them will not be associated with any pathology. Thrombocytopenia in pregnancy can be due to either gestational thrombocytopenia (GT) or obstetric disorders like hypertensive disorders of pregnancy [(preeclampsia, eclampsia and its complications such as hemolysis elevated liver enzymes and low platelets (HELLP)], amniotic fluid embolism, disseminated intravascular coagulopathy (DIC) or medical causes like thrombotic thrombocytopenic purpura (TTP)/ hemolytic uremic syndrome (HUS), autoimmune disorders: systemic lupus erythematosus (SLE), idiopathic thrombocytopenic purpura (ITP), antiphospholipid syndrome, infections, sepsis, hypersplenism, primary bone marrow dysfunction. Other causes are spurious/pseudo thrombocytopenia or drug induced thrombocytopenia. ${ }^{1}$

Gestational thrombocytopenia is a clinically benign thrombocytopenic disorder usually occurring in late pregnancy. It resolves spontaneously after delivery. 
Assessment of individual cases of thrombocytopenia in pregnancy focuses on excluding important underlying causes and weighing risks of bleeding in both mother and baby against hazards of diagnostic and therapeutic interventions. ${ }^{8}$

\section{METHODS}

It is a hospital based prospective observational study over a period of 1 year from September 2018 to August 2019. All pregnant women who attended OPD at the department of obstetrics and gynecology, UPUMS, Saifai for antenatal checkup were included for the study and blood sample was withdrawn. Platelet count was performed using manual method and automated hematology method. Total number of cases studied are 90, selected according to platelet count at admission.

\section{Inclusion criteria}

- All pregnant women were included in the study

- Pregnancy with a previous history of ITP.

\section{Exclusion criteria}

- Pregnant or non- pregnant women having diabetes or thrombo-embolic disorders were excluded from the study.

It is a prospective observational study conducted over a period of 1 year. All pregnant women who attended OPD in department of obstetrics and gynecology were included in the study. Out of these 90 cases were studied in detail.

Details were entered in the proforma regarding the detailed history of period of gestation, high risk factors, past history, complications- during present and past pregnancy. History of petechiae, bruising, drug usage, viral infection, thrombocytopenia in previous pregnancy was taken. General, systemic and obstetric examination was done. All women were subjected to blood test for $\mathrm{Hb}$, TLC, DLC, bleeding time, clotting time, RFT, LFT, HBsAg and HIV. Women with fever were tested for Dengue IgM. Coagulation tests (PT, APTT, FDP and fibrinogen) were done in those with signs or symptoms of DIC. Blood specimen were withdrawn with minimal stasis from the ante-cubital vein using a dry sterile disposable syringe and needle. $3 \mathrm{~mm}$ of blood is taken into EDTA tubes. The specimens were labelled properly. The samples were kept at room temperature until processed within 4 hours of collection.

\section{Laboratory analysis}

Platelet count was performed using manual method and automated haematology method.

Presenting complaints were noted, the cases followed up for any changes in platelet count and associated complaints. Any complications during delivery, maternal and fetal outcome were noted. Maternal outcome regarding mode of delivery, postpartum period was observed. Fetal outcome regarding birth weight, NICU admission, early neonatal outcome noted and were followed up for any complications.

\section{RESULTS}

Out of 263 cases enrolled for study, 90 women were found to have thrombocytopenia, and 173 had normal platelet count. Thus, incidence of thrombocytopenia was $34 \%$.

Table 1: Demographic and obstetrical profile.

\begin{tabular}{|c|c|c|c|}
\hline \multicolumn{2}{|l|}{ Parameters } & $\begin{array}{l}\text { No. of } \\
\text { cases }\end{array}$ & $\%$ \\
\hline \multirow{3}{*}{$\begin{array}{l}\text { Gestational age } \\
\text { (weeks) }\end{array}$} & $29-32$ & 29 & $32.22 \%$ \\
\hline & $33-36$ & 42 & $46.66 \%$ \\
\hline & $37-40$ & 19 & $21.11 \%$ \\
\hline \multirow{3}{*}{$\begin{array}{l}\text { Severity of } \\
\text { thrombocytopenia }\end{array}$} & Mild & 32 & $35.55 \%$ \\
\hline & Moderate & 22 & $24.44 \%$ \\
\hline & Severe & 36 & $40 \%$ \\
\hline \multirow{3}{*}{ Parity of patients } & Primigravidae & 37 & $41.11 \%$ \\
\hline & $2^{\text {nd }}-4^{\text {th }}$ gravid & 48 & $53.33 \%$ \\
\hline & $>4^{\text {th }}$ gravid & 5 & $5.55 \%$ \\
\hline
\end{tabular}

Table 1 shows demographic and obstetrical profile. During the study period records revealed that 42 women (46.66\%) belonged to gestational age of 33-36 weeks, 29 women $(32.22 \%)$ belonged to gestational age of $29-32$ weeks and 19 women $(21.11 \%)$ belonged to gestational age of 37-40 weeks.

Table 2: Etiology of thrombocytopenia in pregnancy.

\begin{tabular}{|c|c|c|}
\hline Causes & $\begin{array}{l}\text { No. of } \\
\text { cases }\end{array}$ & $\%$ \\
\hline Gestational & 45 & $50 \%$ \\
\hline Obstetrics & 23 & $25.56 \%$ \\
\hline (a) Hypertensive disorders & 20 & $22.44 \%$ \\
\hline Preeclampsia & 17 & $18.89 \%$ \\
\hline Eclampsia & 3 & $3.3 \%$ \\
\hline (b) DIC & 3 & $3.3 \%$ \\
\hline Medical & 22 & $24.44 \%$ \\
\hline (a) Hypersplenism & 2 & $2.22 \%$ \\
\hline (b) Hepatic diseases & 3 & $3.33 \%$ \\
\hline (c) Dengue & 5 & $5.55 \%$ \\
\hline (d) Megaloblastic anaemia & 2 & $2.22 \%$ \\
\hline (e) ITP & 10 & $11.11 \%$ \\
\hline
\end{tabular}

Thirty-six (40\%) cases had severe thrombocytopenia, 22 women $(24.44 \%)$ had moderate and 32 women $(35.55 \%)$ had mild thrombocytopenia. In parity wise distribution 37 women $(41.11 \%)$ were primigravidae, 48 cases $(53.33 \%)$ belonged to gravidae $2^{\text {nd }}$ to $4^{\text {th }}$ and 5 cases $(5.55 \%)$ had $>4^{\text {th }}$ gravidae. 
Table 2 shows that gestational thrombocytopenia accounted for majority of cases of thrombocytopenia in pregnancy $(50 \%)$ followed by hypertensive disorders $(22.4 \%)$. It was further followed by ITP $(11.11 \%)$ and dengue $(5.5 \%)$.

Other causes were DIC (3.3\%), hypersplenism (2.2\%), hepatic disease $(3.3 \%)$, megaloblastic anemia $(2.2 \%)$.
Table 3 shows maternal and fetal outcome in which most of the patients $52(57.78 \%)$ had no morbidity. In this study among maternal morbidity 8 cases $(8.88 \%)$ had massive haemorrhage, 6 cases $(6.66 \%)$ had puerperal sepsis, 5 cases $(5.55 \%)$ had renal failure, 7 patients $(7.78 \%)$ went into DIC, 9 patients $(10 \%)$ developed pulmonary edema and 2 cases $(2.2 \%)$ underwent obstetrical hysterectomy.

Table 3: Maternal and fetal outcome.

\begin{tabular}{|c|c|c|c|c|}
\hline Outcome & & Cause & No. of cases & $\%$ \\
\hline \multirow{7}{*}{ Maternal } & No morbidity & Nil & 52 & $57.78 \%$ \\
\hline & \multirow{6}{*}{ Morbidity } & Massive haemorrhage & 8 & $8.88 \%$ \\
\hline & & Puerperal sepsis & 6 & $6.66 \%$ \\
\hline & & ARF (renal failure) & 5 & $5.55 \%$ \\
\hline & & DIC & 7 & $7.78 \%$ \\
\hline & & Pulmonary edema & 9 & $10 \%$ \\
\hline & & Obstetrical hysterectomy & 2 & $2.22 \%$ \\
\hline \multirow{7}{*}{ Perinatal } & No morbidity & Nil & 49 & $54.44 \%$ \\
\hline & \multirow{4}{*}{ Morbidity } & FGR & 10 & $11.11 \%$ \\
\hline & & Birth asphyxia & 9 & $10 \%$ \\
\hline & & Severe thrombocytopenia & 9 & $10 \%$ \\
\hline & & $\mathrm{ICH}$ & 4 & $4.44 \%$ \\
\hline & \multirow{2}{*}{ Mortality } & IUD & 4 & $4.44 \%$ \\
\hline & & Still birth & 5 & $5.55 \%$ \\
\hline
\end{tabular}

In this study 49 cases (54.4\%) had no perinatal morbidity. The various perinatal morbidities which we reported in this study are fetal growth restriction in 10 cases $(11.11 \%)$, Birth asphyxia in 9 cases $(10 \%)$, severe thrombocytopenia in 9 cases $(10 \%)$, intracranial haemorrhage in 4 cases $(4.4 \%)$, stillbirth in 5 cases $(5.5 \%)$ and IUD in 4 cases $(4.4 \%)$.

In this study $60 \%$ cases delivered by LSCS and $40 \%$ cases delivered vaginaly.

\section{DISCUSSION}

In the present study prevalence of thrombocytopenia came out to be $18.0 \%$. Various causes of thrombocytopenia in pregnancy found were gestational thrombocytopenia (GT), ITP, pre-eclampsia and its complications -HELLP, dengue, SLE and drug induced thrombocytopenia. Gestational thrombocytopenia (GT) accounted for majority of cases $(50 \%)$ followed by hypertensive disorders of pregnancy $(22.4 \%)$ which was further followed by ITP $(11.1 \%)$. Other minor causes were dengue, hepatic disease and megaloblastic anaemia. Prevalence of Gestational thrombocytopenia was $11.8 \%$.

Prevalence of thrombocytopenia in several other studies varies from 6 to $12 \%$. In initial studies by Burrows RF and Kelton JG2 prevalence was reported as around 7.6\%. Shehata $\mathrm{N}$ et al prospectively studied different causes of thrombocytopenia in pregnancy with a large sample size. ${ }^{1}$ In her study, prevalence of GT among thrombocytopenia was found to be $73.6 \%$ and of preeclampsia/eclampsia/ HELLP was $21 \%$. Immune disorders of pregnancy accounted for $4.1 \%$ cases while other causes like DIC/ TTP accounted for $1.3 \%$ cases. Boehlen $\mathrm{F}$ et al studied thrombocytopenia and again, and prevalence was reported as $11 \%$ and $6-11 \%$ respectively with GT being the most common cause. ${ }^{9,10}$ In study by Sanio $\mathrm{S}$ et al, prevalence was found to be $7.3 \%{ }^{6}$ Karim $\mathrm{R}$ et al, reported that thrombocytopenia was observed in $7 \%$ to $10 \%$ pregnancies. ${ }^{5}$ According to the study by Mc Crae $\mathrm{KR}$ et al, thrombocytopenia affects $6-10 \%$ of all pregnant females. Singh $\mathrm{N}$ et al, reported prevalence of thrombocytopenia in pregnancy as $8.8 \%{ }^{7}$ GT was seen in $64.2 \%$ cases, obstetric causes were found in $22.1 \%$ cases and medical causes in $13.68 \%$ cases. Hypertensive and hepatic disorders were the most common obstetric causes of thrombocytopenia. Parnas $\mathrm{M}$ et al reported the main causes of thrombocytopenia as gestational thrombocytopenia $(59.3 \%)$, ITP $(11.05 \%)$, preeclampsia $(10.05 \%)$, and HELLP syndrome $(12.06 \%)$. Khellaf M et al, reported that occurrence of thrombocytopenia during pregnancy is frequent and is around $10 \%$ and GT dominates among all causes of thrombocytopenia in pregnancy. ${ }^{4}$

Ozkan $\mathrm{H}$ et al reviewed 29 women with ITP and stated that majority of deliveries were vaginal and none of the neonates had complications attributable to the mode of 
delivery. Burrows RF and Kelton JG et al, conducted a prospective study for 1 year on a group of women who delivered at McMaster university and demonstrated that gestational thrombocytopenia appears to have no adverse effects on either mothers or their infants. ${ }^{2}$ Also, obstetrical interventions like caesarean section because of thrombocytopenia are not justified in these mothers. In a prospective study by Ruggeri $M$ et al, 37 consecutive patients with GT were enrolled, with a total of 41 pregnancies observed. Vaginal delivery carried out in $33 / 41(80 \%)$ whereas $8 / 41(20 \%)$ had caesarean for obstetric indications. Two patients received blood transfusion for PPH (atonic). Neonatal bleeding didn't occur in any delivery. Webert $\mathrm{KE}$ et al, did retrospective analysis of obstetric patients with ITP. 92 women with ITP were studied. Women in 37 pregnancies (31.1\%) required treatment to increase platelet counts. Most deliveries $(82.4 \%)$ were vaginal and bleeding at delivery was uncommon. 18 infants $(14.6 \%)$ required treatment for hemostatic impairment with 2 fetal deaths reported. One was due to hemorrhage. ITP in pregnancy carries a low risk, but mothers and infants may require therapy to raise their platelet counts. Suri V et al did a retrospective study in which 16 patients with ITP were studied. There was no postpartum hemorrhage or maternal death. None of the neonates had bleeding complications, irrespective of mode of delivery. They concluded that pregnant patients with ITP have generally good maternal and perinatal outcomes. Singh N et al, reported that mode of delivery was not affected by thrombocytopenia. ${ }^{7}$ Maternal morbidity and mortality was seen in only medical and obstetric causes of thrombocytopenia.

The present study showed that patients with thrombocytopenia in pregnancy were at a risk of preterm (less than 37 weeks) delivery $(78.88 \%$ ) which is due to increase need for labor induction in face of obstetrical complications.

Thrombocytopenia itself causes complications and thrombocytopenia is a complication of other disorders. Pulmonary edema $(10 \%)$ and maternal hemorrhage $(8.88 \%)$ is the most common complication. According to this study $38(42.23 \%)$ cases had complications which include puerperal sepsis $(6.66 \%)$, ARF $(5.55 \%)$, DIC $(7.78 \%)$ and obstetrical hysterectomy $(2.2 \%)$. According to study conducted by Amita D. Incidence of PPH was $9.89 \%$ among cases. PPH was seen in $30 \%$ of medical, $15 \%$ of obstetric and only $4.92 \%$ of gestational thrombocytopenia. Incidence was significantly higher in medical thrombocytopenia $(\mathrm{p}=0.008)$. Three cases of obstetric and two of medical thrombocytopenia died during the study giving a mortality rate of $5.26 \%$. Significantly higher mortality $(p=0.009)$ was seen in these cases as compared to GT that showed nil mortality.

In this study perinatal morbidity was present in 41 patients $(45.56 \%)$. The perinatal complications include fetal growth restriction in 10 patients $(11.1 \%)$, birth asphyxia in 9 patients $(10 \%)$, severe thrombocytopenia in
9 patients $(10 \%), \mathrm{ICH}$ in 4 cases $(4.4 \%)$. In this study 9 patients had perinatal mortality in which 4 cases had IUD and 5 cases had stillbirth. Neonatal complications are not directly related to maternal platelet count. The fetal complications occur in cases of preterm delivery, abruption, thrombocytopenia associated with anemia, sepsis.

According to study conducted by Singh N, out of the 91 newborns, platelet count assessment could be done in 75 (81.4\%). All had normal platelet counts at birth except the one born to mother with ITP. Neonatal thrombocytopenia of 65,000 cumm on day-1 returned to normal on day eight. None of the babies had any bleeding complications.

In this study $40 \%$ cases had severe thrombocytopenia and $10 \%$ babies had severe thrombocytopenia. Gestational thrombocytopenia does not adversely affect maternal and fetal outcome. Study findings were similar to study conducted by Kamphuis et al. ${ }^{11}$ Samuels evaluated 162 pregnant women and their infants with thrombocytopenia, 74 with presumed GT. No infant from a GT gravida had a platelet count $<50,000 / \mu \mathrm{L}$ or intracranial haemorrhage. ${ }^{12}$ In Burrows' study 756 of 1027 women, who were thrombocytopenic $(73.6 \%)$ had GT. Only 1 infant had a platelet count $<50,000 / \mu \mathrm{L}$ and this infant had trisomy 21 and congenital bone marrow dysfunction. He concluded that GT is the most frequent type of thrombocytopenia and poses no apparent risks for either the mother or infant. ${ }^{13}$

In Burrows' study of women with thrombocytopenia, 216 had preeclampsia with HELLP and 5 gave birth to infants with severe thrombocytopenia, all were preterm. Out of five, two infants experienced intracranial haemorrhages. ${ }^{13}$ Cook in his review of ITP study in pregnant patients reported severe thrombocytopenia in 6 out of 32 infants. ${ }^{14}$ In large series of maternal platelet counts $(15,607$ samples) over a 6-year period at McMaster University, Burrows found that out of 46 women with ITP, 4 infants had severe thrombocytopenia. Three of these were delivered vaginally and 1 by caesarean delivery. No infant experienced an intracranial hemorrhage. ${ }^{13}$ Payne in his 10-year experience reviewed 55 newborns born to 41 women who had ITP. Two were associated with complications- one had fetal bradycardia and other had an umbilical cord hematoma with fetal distress resulting in with anoxic encephalopathy and cerebral palsy in infant. ${ }^{15}$

According to this study 29 cases delivered between 29 to 32 weeks, 42 cases delivered between 33 to 36 weeks and 19 cases delivered at term. Mode of delivery was not influenced by platelet count. $48 \%$ cases delivered by LSCS and $52 \%$ cases by vaginal delivery. LSCS was done for obstetric and medical conditions like previous LSCS, fetal distress, failed induction etc. According to study conducted in Kolkata, 91 cases delivered during the study. $68.1 \%$ delivered at term whereas $31.9 \%$ delivered 
preterm. $61.54 \%$ had normal vaginal delivery, $36.26 \%$ had CS and $2.2 \%$ had instrumental delivery. All the cesarean sections were performed for obstetric/medical causes and none for thrombocytopenia.

\section{CONCLUSION}

Gestational thrombocytopenia is the most common cause of thrombocytopenia during pregnancy $(50 \%)$, but other underlying causes must be considered as well. A thorough history and physical examination will rule out most causes look at the remainder of $\mathrm{CBC}$ and smear to rule out pancytopenia and platelet clumping associated with pseudo thrombocytopenia.

If no antecedent history of thrombocytopenia is present and platelet counts are above $70,000 / \mathrm{mcL}$, the condition is more likely to be GT. If platelet counts fall below $50,000 / \mathrm{mcL}$ or if a pre-existing history of thrombocytopenia is present, the condition is more likely to be ITP.

There is a positive correlation between thrombocytopenia with adverse feto-maternal outcome. Therefore, monitor platelet count periodically. Proper antenatal care and institutional deliveries enable obstetricians to diagnose thrombocytopenia and its complication at an early stage and early intervention results in better outcome. further studies are required to screen high risk population with thrombocytopenia to make the effective screening and management program

\section{ACKNOWLEDGMENTS}

Authors would like to thank Dr. Kalpana Kumari for her exemplary guidance, valuable feedback and constant encouragement throughout the duration of the research work. Her valuable suggestions were of immense help throughout this work. Authors would also like to thank Dr. Vandana Verma for her help and guidance in this research work.

Funding: No funding sources

Conflict of interest: None declared

Ethical approval: Not required

\section{REFERENCES}

1. Shehata N, Burrows RF, Kelton JG. Gestational Thrombocytopenia. Clin Obstet Gynecol. 1999;42:327-34.

2. Burrows RF, Kelton JG. Thrombocytopenia at delivery: a prospective survey of 6715 deliveries. Am J Obstet Gynecol. 1990;162(3):731-4.
3. Kadir RA, McLintock C. Thrombocytopenia and disorders of platelet function in pregnancy. Semin Thromb Hemost. 2011;37(6):640-52.

4. Khellaf M, Loustau V, Bierling P, Michel M, Godeau B. Thrombocytopenia and pregnancy. Rev Med Interne. 2012;33(8):446-52.

5. Karim R, Sacher RA. Thrombocytopenia in pregnancy. Curr Hematol Rep. 2004;3(2):128-33.

6. Sainio S, Kekomaki R, Rikonen S, Teramo K. Maternal thrombocytopenia at term: a populationbased study. Acta Obstet Gynaecol Scand. 2000;79(9):744-9.

7. Singh N, Dhakad A, Singh U, Tripathi, Sankhwar P. Prevalence and characterization of thrombocytopenia in pregnancy in Indian Women. Indian $\mathrm{J}$ Hematol Blood Transfus. 2012;28:77-81.

8. Wei J, Liu GL, Liang MY, Wang SM. Effect of general anesthesia used in cesarean section on maternal-neonatal outcome of pregnancy complicated with severe thrombocytopenia. Zhonghua Fu Chan KeZaZhi. 2009;44(9):665-8.

9. Boehlen F, Hohlfeld P, Extermann P, Perneger TV, de Moerloose P. Platelet count at term pregnancy: a reappraisal of the threshold. Obstet Gynecol. 2000;95(1):29-33.

10. Boehlen F. Thrombocytopenia during pregnancy. importance, diagnosis and management. Hemostaseol. 2006;26:72-4.

11. Kamphuis MM, Oepkes D. Fetal and neonatal alloimmunre thrombocytopenia: prenatal interventions. Prenat Diagn. 2011;31(7):712-9.

12. Samuels P, Bussel JB, Braitman LE. Estimation of the risk of thrombocytopenia in the offspring of pregnant women with presumed immune thrombocytopenic purpura. $\mathrm{N}$ Engl J Med. 1990;323(4):229-35.

13. Burrows RF, Kelton JG. Fetal thrombocytopenia and its relation to maternal thrombocytopenia. N Engl J Med. 1993;329(20):1463-6.

14. Cook RL, Miller RC, Katz VL, Cefalo RC. Immune thrombocytopenic purpura in pregnancy: a reappraisal of management. Obstet Gynecol. 1991;78(4):578-83.

15. Payne SD, Resnik R, Moore TR, Hedriana HL, Kelly TF. Maternal characteristics and risk of severe neonatal thrombocytopenia and intracranial haemorrhage in pregnancies complicated by autoimmune thrombocytopenia. Am J Obstet Gynecol. 1997;177(1):149-55.

Cite this article as: Singh J, Kumari K, Verma V. Study of thrombocytopenia in pregnancy: clinical presentation and outcome at tertiary care rural institute. Int J Reprod Contracept Obstet Gynecol 2020;9:1622-6. 